\title{
IMMUNOHISTOCHEMICAL EXPRESSION OF P53 IN INVASIVE DUCTAL CARCINOMA OF BREAST IN PAKISTANI WOMEN
}

\author{
Umair Aslam Shahzad Khan, Muhammad Tahir Khadim*, Syed Salman Ali**, Muhammad Imran Khan Wajid***, \\ Akhter Ali Bajwa****, Saba Anjum***** \\ Combined Military Hospital Gilgit/National University of Medical Sciences (NUMS) Pakistan, *National University of Medical Sciences \\ (NUMS) Pakistan, ${ }^{* *}$ Combined Military Hospital Abbottabad/National University of Medical Sciences (NUMS) Pakistan, ${ }^{* * * C o m b i n e d ~}$ \\ Military Hospital/National University of Medical Sciences (NUMS) Rawalpindi Pakistan, ${ }^{* * * *}$ Combined Military Hospital Multan/National \\ University of Medical Sciences (NUMS) Pakistan, ${ }^{* * * *}$ Armed Forces Institute of Pathology/National University of Medical Sciences (NUMS) \\ Rawalpindi Pakistan
}

\begin{abstract}
Objective: To determine the frequency of immunohistochemical expression of $p 53$ in invasive ductal carcinoma of breast in Pakistani women.

Study Design: Descriptive, cross-sectional study.

Place and Duration of Study: Department of Histopathology, Combined Military Hospital, Lahore, from Jul 2015 to Jan 2016.

Methodology: This study involved 80 histopathological samples of invasive ductal carcinoma breast which were tested for p53 expression. Sample size with 80 cases was calculated using 95\% confidence level and $10 \%$ margin of error while expected percentage of p53 expression will be $71.67 \%$. Specimens were selected by non-probability, consecutive sampling. All specimens of newly diagnosed cases of invasive ducal carcinoma at CMH Lahore on histopathological examination of female patients aged between 15-80 years. IHC application of p53 was done as per technique mentioned in the manual given by the DAKO.

Results: Patient age was calculated which was between 25 years and 80 years while mean age was $50.76 \pm 11.80$ years. Majority of the patients were aged between $25-50$ years $(n=44,55.0 \%)$. In $54(67.5 \%)$ patients lymph nodes were positive for tumor metastasis. Majority $64(80 \%)$ of the tumors were Grade-II followed by Grade-III in 15 $(18.7 \%)$ patients. The size of the tumor ranged from $0.2 \mathrm{~cm}$ to $14 \mathrm{~cm}$ with a mean of $4.16 \pm 2.59 \mathrm{~cm}$. p53 expression was positive in $38(47.5 \%)$ patients. The expression of $p 53$ was higher in patients who have positive lymph nodes $(59.3 \%$ vs. $23.1 \% ; p=0.002)$. However, expression of $p 53$ was not so significant for age $(p=0.079)$, tumor size $(p=0.414)$ and tumor grade $(p=0.176)$ groups.

Conclusion: The frequency of p53 expression was found to be $47.5 \%$ in invasive mammary cancer in Pakistani population. The expression of $p 53$ was higher in patients who have positive lymph nodes $(59.3 \%$ vs. $23.1 \%$; $p=0.002)$. However, expression of $p 53$ was not so significant for age $(p=0.079)$, tumor size $(p=0.414)$ and tumor grade $(p=0.176)$ groups.
\end{abstract}

Keywords: Immunohistochemical expression, Invasive ductal carcinoma, $p 53$.

This is an Open Access article distributed under the terms of the Creative Commons Attribution License (http://creativecommons.org/licenses/by/4.0), which permits unrestricted use, distribution, and reproduction in any medium, provided the original work is properly cited.

\section{INTRODUCTION}

Breast cancer is the most common cancer in women in western world 1 . Incidence of breast cancer in Pakistani women is $24.4 \%$ which makes it the most common cancer among Pakistani women $^{2}$. Carcinoma of breast is a heterogeneous disorder with multiple biological types, natural course, pathological and molecular characteristics

Correspondence: Dr Umair Aslam Shahzad Khan, Consultant Pathologist, CMH Gilgit Pakistan

Received: 01 Jul 2019; revised received: 23 Aug 2019; accepted: 27 Aug 2019 with different prognostic factors ${ }^{3}$. Carcinoma of the breast is a complex disease. There is large intertumoral and intratumoral variations which causes variable clinical course and response to treatment ${ }^{4}$.

TP53 causes progression of tumour by two mechanisms. Firstly it reduces tumour suppression. Secondly it is a pro-oncogene. Due to these mechanisms, p53 leads to tumorigenic effects 5 . TP53 gene can be measured by immuno-histochemistry due to longer half-life ${ }^{1}$. TP53 mutation is also related to response to various anticancer 
therapies. Breast carcinoma with TP53 mutation respond in a variable way to anticancer therapy due to different reasons 5 . After DNA damage induced by anticancer therapies, apoptosis is controlled by TP53 gene. After inducing DNA damage, radiotherapy and chemotherapy uses apoptotic ability of TP53. Breast cancer with TP53 mutation will be more resistant to radiation and chemotherapy. Hence $p 53$ function loss is related to poor response to chemotherapy and endocrine therapy. $p 53$ expression is also related with a poor prognosis in breast carcinoma and patient with $p 53$ expression also presents with high grade tumour and lymph node invasion 1 .

Different studies have shown different percentages of $p 53$ mammary carcinoma ${ }^{6}$. A research conducted in India overexpression of p53 was noted in $22 \%$ cases of invasive ductal carcinoma ${ }^{1}$. In another study carried out in Romania, immunohistochemical expression of $p 53$ was present in $44.44 \%$ of all invasive ductal carcinoma patients ${ }^{6}$. In one of the studies carried out in India, p53 was positive in $71.67 \%$ of invasive ductal carcinoma 7

Rationale of the study was to determine the expression of $p 53$ in invasive ductal carcinoma in Pakistani population as invasive ductal carcino$\mathrm{ma}$ is common malignancy in Pakistan and p53 would help to determine prognosis and response to therapy.

\section{METHODOLOGY}

This research was conducted at Pathology department of CMH Lahore between July 2015 to January 2016. Ethical committee approval was taken. A total of 80 females, with newly diagnosed invasive ductal carcinoma of breast, who aged between 25-80, were included in the study by non probability, consecutive sampling technique. Poorly fixed specimens and specimens with scanty tumor tissue, or patients on treatment were not included in the study.WHO calculator was used to calculate the sample. Confidence interval was $95 \%$, while error margin was $10 \%$. Expected percentage of $p 53$ expression was taken as $71.67 \%$.

IHC expression for p53 was done by DAKO kit as per the guidelines as follows: The FFPE tissue sections were cut at $3 \mu \mathrm{m}$ thickness and placed on clean glass slide with pre-attached adhesive on its surface. They were incubated at 58 degrees Celsius for 4 hours. The sections were deparaffinized with xylene 1 and 2, for 3 minutes each. They were rehydrated in decreasing concentrations of alcohol, $90 \%, 80 \%$ and $70 \%$ for 3 minutes each, followed by running tap water for 5 seconds. The slides were placed in coplin jar with 0.01 MTris-EDTA at 9.0pH. 750W domestic microwave was used to treat the slides for 20-30 minutes for heat mediated antigen retrieval. Slides were washed with distilled water for 20-40 minutes. After cooling down the sections, they were brought to phosphate buffered saline (PBS) at $\mathrm{pH} 7.3$ for 5 minutes. PBS was washed and excess was wiped off the sections. Endogenous peroxidase activity blocked by incubating in $0.5 \%$ hydrogen peroxide in methanol for 5 minutes. $100 \mathrm{uL}$ of primary antibody of $p 53$ was instilled on the sections and incubated for 60 minutes. The slides were again washed in three series of PBS for one hours. The slides were then incubated in avidin-biotin complex for 10 minutes. They were rinsed with distilled water. They were incubated in DAB (diaminobenzidine). Then the slides were put under water and counter stained with haematoxylin for 40 seconds. The slides were dehydrated by $70 \%, 80 \%, 90 \%$ and $100 \%$ alcohol for $3 \mathrm{mi}-$ nutes each. Clearing was done by placing slides in xylene for 3 minutes. The slides were mounted with Canada balsam. IHC results were verified by two histopathologiston high power, by calculating the proportion of tumor cells with nuclear stain. Any value above $10 \%$ of tumor cells was taken as positive?.

Data was entered and statistically interpreted using SPSS version 22. Numerical variables which includes age are shown as mean \pm SD. Categorical variables which include expression of $p 53$ are shown as frequency and percentage. Stratification of data is done for age, lymph node positivity/negativity, size of tumor and grade to address effect modifiers. Post stratification Chisquare was taking $p$-value $\leq 0.05$ as significant. 


\section{RESULTS}

In the present study, the age of the patients ranged from 25 years to 80 years with a mean of $50.76 \pm 11.80$ years. A similar mean age among observed much higher frequency of Grade-I tumours $(48 \%)$ followed by Grade-II $(40 \%)$ tumours with only a small proportion of Grade-III tumours $(12.0 \%)$.

Table: Stratification of $p 53$ expression according to age groups, lymph node status, tumour grade and tumour size.

\begin{tabular}{|c|c|c|c|c|c|}
\hline \multirow{2}{*}{$\begin{array}{l}\text { Clinicopathological } \\
\text { Variable }\end{array}$} & \multirow{2}{*}{$\begin{array}{l}\text { Cases } \\
\text { (n) }\end{array}$} & \multirow{2}{*}{$\begin{array}{c}\text { Percentage } \\
(\%)\end{array}$} & \multicolumn{2}{|c|}{$p 53$ Expression } & \multirow{2}{*}{$p$-value } \\
\hline & & & Positive & Negative & \\
\hline \multicolumn{6}{|c|}{ Age Groups (years) $(n=80)$} \\
\hline $25-50$ & 44 & 55 & $17(38.6 \%)$ & $27(61.4 \%)$ & \multirow{2}{*}{0.079} \\
\hline $51-80$ & 36 & 45 & $21(58.3 \%)$ & $15(41.7 \%)$ & \\
\hline \multicolumn{6}{|c|}{ Lymph Node Status $(\mathrm{n}=\mathbf{8 0})$} \\
\hline Positive & 54 & 67.5 & $32(59.3 \%)$ & $22(40.7 \%)$ & \multirow{2}{*}{0.002} \\
\hline Negative & 26 & 32.5 & $6(23.1 \%)$ & $20(76.9 \%)$ & \\
\hline \multicolumn{6}{|l|}{ Tumour Grade $(n=80)$} \\
\hline Grade-I & 1 & 1.3 & $0(0.0 \%)$ & $1(100 \%)$ & \multirow{3}{*}{0.176} \\
\hline Grade-II & 64 & 80 & $28(43.8 \%)$ & $36(56.2 \%)$ & \\
\hline Grade-III & 15 & 18.7 & $10(66.7 \%)$ & $5(33.3 \%)$ & \\
\hline \multicolumn{6}{|l|}{ Tumour Size $(n=80)$} \\
\hline$<4 \mathrm{~cm}$ & 52 & 65 & $22(42.3 \%)$ & $30(57.7 \%)$ & \multirow{3}{*}{0.414} \\
\hline $4-9 \mathrm{~cm}$ & 22 & 27.5 & $13(59.1 \%)$ & $9(40.9 \%)$ & \\
\hline $9-14 \mathrm{~cm}$ & 6 & 7.5 & $3(50 \%)$ & $3(50 \%)$ & \\
\hline
\end{tabular}

patients of invasive ductal carcinoma breast has been reported by Badar et al ${ }^{8}$, in 2014 (48.6 \pm 12.2 years), Khokher et al ${ }^{9}$, in 2012 (47 \pm 12 years) and Mamoon et al10, in 2009 (48 \pm 12 years). In 54 $(67.5 \%)$ patients lymph nodes were positive for tumour metastasis. A similar proportion of positive lymph node status at presentation among patients of invasive ductal carcinoma breast has been reported by Badar et al, 8 (62.0\%), Mamoon et al, 10 (74.6\%) and Radha et al, 1 (52.0\%).

Majority $64(80 \%)$ of the tumours were Grade-II followed by Grade-III in 15 (18.7\%) patients. Siddiqu et al11, and Khokher et al ${ }^{9}$, also reported Grade-II being the most frequent tumour grade observed in $65 \%$ and $55 \%$ of such patients at presentation respectively. Badar et al ${ }^{8}$, observed relatively equal proportion of grade-II $(41.4 \%)$ and Grade-III (49.6\%) tumours among patients presenting with invasive ductal carcinoma at Shaukat Khanum Memorial Cancer Hospital and Research Center, Lahore. Kakarala et $a l^{12}$, also reported a relatively similar distribution of tumour grade among Indian such patients; Grade-II (40.8), Grade-III (41.9\%). Radha et $a^{1}$,

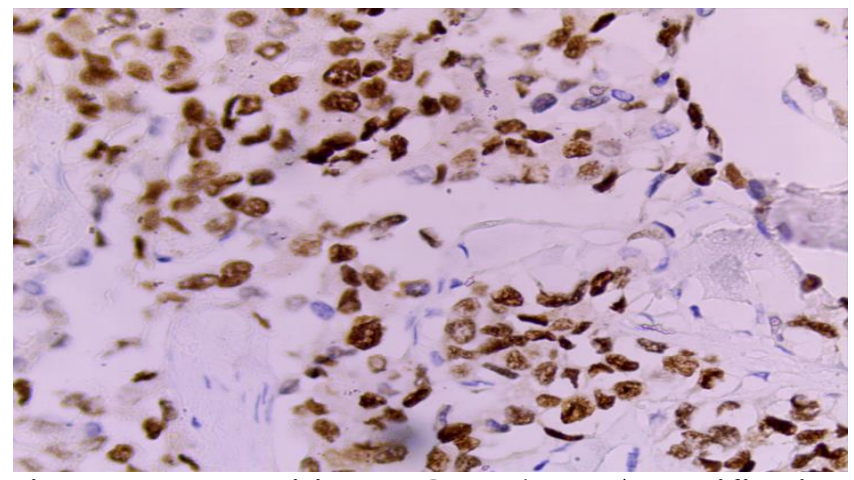

Figure-1: $p 53$ positive IDC grade-III (magnification 40x).

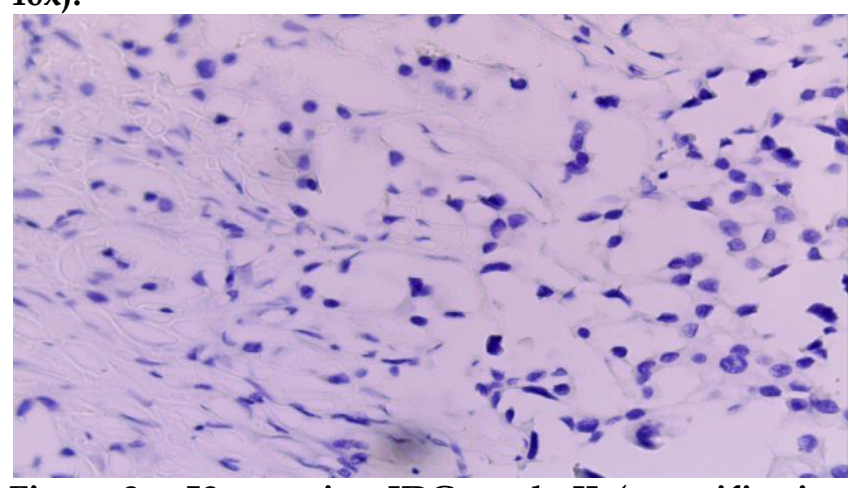

Figure-2: $p 53$ negative IDC grade-II (magnification 20x). 
The size of the tumour ranged from $0.2 \mathrm{~cm}$ to $14 \mathrm{~cm}$ with a mean of $4.16 \pm 2.59 \mathrm{~cm}$. Mamoon et $a l^{10}$, mentioned same tumour of $4.6 \pm 2 \mathrm{~cm}$ among such patient at Armed Forces Institute of Pathology, Rawalpindi, Pakistan.

p53 expression was positive in 38 (47.5\%) patients (fig- $1 \& 2$ ). The frequency of $p 53$ was significantly higher in samples with positive lymph node status ( $59.3 \%$ vs. $23.1 \%$; $p=0.002$ ). However, expression of p53 was not so significant for age $(p=0.079)$, tumor size $(p=0.414)$ and tumor grade $(p=0.176)$ groups.

\section{DISCUSSION}

In the present study $p 53$ expression was positive in $38(47.5 \%)$ patients. It was negative in $42(52.5 \%)$ patients. Our results match with those of Plesan et al. In 2010 who reported similar frequency of p53 expression among Romanian such patients $^{6}$. Previously Lipponen et al ${ }^{13}$, (1995) also reported similar frequency of $p 53$ expression in Finland patients. A much higher expression of p53 in invasive mammary cancer has been reported by Bertheau et al14, in 2013 (69\%) among French and Sekar et al , in $2014(71.67 \%)$ among Indian such patients. While Radha et al ${ }^{1}$, in 2014 (22\%), Yamamoto et al 15 , in $2014(21.0 \%)$ and Yang et al ${ }^{16}$, in $2013(29.9 \%)$ reported relatively lower frequencies of p53 expression among Indian and Chinese such cases.

The frequency of $p 53$ was significantly higher in samples with positive lymph node status (59.3\% vs. $23.1 \% ; p=0.002)$. However, expression of $p 53$ was not so significant for age $(p=0.079)$, tumor size $(p=0.414)$ and tumor grade $(p=0.176)$ groups.. Previously, Sirvent et al17, in 1995 reported insignificant difference in the $p 53$ expression with lymph node status $(p>0.05)$. But they reported significant difference across tumour grade $(p=$ 0.0048 ) where higher tumour grade was associated with increased frequency of $p 53$ expression. Radha et $a l^{1}$, in 2014 did notobserve any difference in $p 53$ expression across age $(p=0.806)$, tumour size $(p=0.947)$, tumour grade $(p=0.940)$ and lymph node status $(p=0.848)$.
The present study is in local population and has found that $47.5 \%$ of breast cancer specimens were positive for $p 53$. The conclsionof the present study matches to various populations with minor differences which can be due to population differences. As known from previous research p53 expression is associated with worst outco$\mathrm{me}^{18}$. Tumour with IHC detected $p 53$ show more metastatic behavior ${ }^{19}$. Several studies have suggested that anti $p 53$ drugs can restore the tumour suppression ability of $p 53$ gene $^{20-23}$. This higher proportion of $p 53$ expression in the present study necessitates routine testing of $p 53$ and anticipated measures in the management of patients with a positive $p 53$ expression so that morbidity and mortality associated with breast cancer can be diminished. A very important finding in the present study was significantly higher proportion of $p 53$ expression in specimens with a positive lymph node status which may imply an association between positive $p 53$ expression and nodal involvement. However, further studies are required in this regard.

The strengths of the this research includes strict exclusion criteria to exclude the confounders and stratification of results for age, tumour size, grade and lymph node status to address effect modifiers which make the present study more reliable. However, there was a very strong limitation to this research that we did not compare the outcome of patients with and without p53 expression.

\section{CONCLUSION}

The frequency of p53 expression was $47.5 \%$ in invasive ductal carcinoma of breast among Pakistani women. It was significantly higher in samples with positive lymph node status $(59.3 \%$ vs. $23.1 \%$; $p=0.002)$. However, significant difference in the frequency of $p 53$ expression across age $(p=0.079)$, tumor size $(p=0.414)$ and tumor grade $(p=0.176)$ groups was not noted.

\section{CONFLICT OF INTEREST}

This study has no conflict of interest to be declared by any author. 


\section{REFERENCES}

1. Jing-ping LI, Zhang XG, Zhang Z, Zheng LH, Association of p53 expression with poor prognosisin patients with triple-negative breast invasiveductal carcinoma, Med 2019; 98(1): 18-21.

2. Parveen S, Sarwar G, Khuwaja M, Ahmed R, Nazeer M. Carcinoma of breast pattern and presentation in developing countries. Pak J Surg 2011; 27(1): 248-49.

3. Makki J. Diversity of Breast Carcinoma: Histological Subtypes and Clinical Relevance, Clin Med Insights Pathol 2015; 8(2): 2331.

4. Makki J, Myint O, Wynn AA, Samsudin AT, John DV. Expression distribution of cancer stem cells, epithelial to mesenchymal transition, and telomerase activity in breast cancer and their association with clinicopathologic characteristics. Clin Med Insights Pathol 2015; 8(1): 1-16.

5. Silwal-Pandit L, Langerød A, Børresen-Dale AL. TP53 mutations in breast and ovarian cancer. Cold Spring HarbPerspect Med 2017; 7(1): a026252-61.

6. Pleşan DM, Georgescu CV, Pătrană N, Pleşan C, Stoica D. Immunohistochemical study of p53 and Ki67 in a group of patients with mammary carcinoma. Rom J Morphol Embryol 2010; 51(2): $459-65$.

7. Sekar P, Bharti JN, Nigam JS, Sharma A, Soni PB. Evaluation of p53, hoxd10, and e-cadherin status in breast cancer and correlation with histological grade and other prognostic factors. J Oncol 2014; 2014(4): 702527-32.

8. Badar F, Mahmood S, Faraz R, Yousaf A, Quader A, Asif H, et al. Epidemiology of breast cancer at the Shaukat Khanum Memorial Cancer Hospital and Research Center, Lahore, Pakistan. J Coll Physicians Surg Pak 2015; 25(10): 738-42.

9. Khokher S, Qureshi MU, Riaz M, Akhtar N, Saleem A. Clinicopathologicproile of breast cancer patients in Pakistan: ten years data of a local cancer hospital. Asian Pacific J Cancer Prev 2012; 13(2): 693-98.

10. Mamoon N, Sharif MA, Mushtaq S, Khadim MT, Jamal S. Breast carcinoma over three decades in northern Pakistan-are we getting anywhere? J Pak Med Assoc 2009; 59(12): 835-38.

11. Siddiqui S, Kayani N, Sulaiman S, Akbar S, Sajid H. Breast carcinoma in pakistani females: a morphological study of 572 breast specimens. J Pak Med Assoc 2000; 50(1): 174-82.

12. Kakarala M, Rozek L, Cote M, Liyanage S, Brenner DE. Breast cancer histology and receptor status characterization in Asian Indian and Pakistani women in the US. A SEER analysis. BMC Cancer 2010; 10(2): 191-95.

13. Lipponen P, Ji H, Aaltomaa S, Syrjänen S, Syrjänen K. p53 protein expression in breast cancer as related to histopathological characteristics and prognosis. Int J Cancer 1993; 55(1): 51-56.

14. Bertheau P, Lehmann-Che J, Varna M, Dumay A, Poirot B, Porcher R, et al. p53 in breast cancer subtypes and new insights into response to chemotherapy. Breast 2013; 22(Suppl-2): S27-29.

15. Yamamoto $M$, Hosoda $M$, Nakano $K$, Jia $S$, Hatanaka $K C$, Takakuwa E, et al. p53 accumulation is a strong predictor of recurrence in estrogen receptor-positive breast cancer patients treated with aromatase inhibitors. Cancer Sci 2014; 105(1): 81-88.

16. Yang P, Du CW, Kwan M, Liang SX, Zhang GJ. The impact of p53 in predicting clinical outcome of breast cancer patients with visceral metastasis. Sci Rep 2013; 3(2): 2246-48.

17. Sirvent JJ, Salvad MT, Santafé M, Martínez S, Brunet J, Alvaro T, et al. p53 in breast cancer. Its relation to histological grade, lymph-node status, hormone receptors, cell-proliferation fraction (ki-67) and c-erbB-2. lmmunohistochemical study of 153 cases. Histol Histopathol 1995; 10(5): 531-39.

18. Bae SY, Nam SJ, Jung Y, Lee SB, Park BW, Lim W, et al. Differences in prognosis and efficacy of chemotherapy by p53 expression in triple-negative breast cancer. BreastCancer Res Treat 2018; 172(2): 437-44.

19. Jasar D, Smichkoska S, Kubelka K, Eskelinen M, Kosma VM, Syrjänen K. Expression of p53 protein product in triple negative breast cancers and relation with clinical and histopathological parameters. Pril (Makedon Akad Nauk Umet Odd Med Nauki) 2015; 36(1): 69-79.

20. Synnott NC, Bauer MR, Madden S, Murray A, Klinger R, O'Donovan N, et al. Mutant p53 as a therapeutic target for the treatment of triple-negative breast cancer: preclinical investigation with the anti-p53 drug, PK11007. Cancer Lett 2018; 414(1): 99-06.

21. Duffy MJ, Synnott NC, Crown J. Mutant p53 in breast cancer: potential as a therapeutic target and biomarker. Breast Cancer Res Treat 2018; 170(2): 213-19.

22. Synnott NC, Murray A, Mcgowan PM, Kiely M, Kiely PA, O'Donovan N, et al. Mutant p53: a novel target for the treatment of patients with triple-negative breast cancer? Int J Cancer 2017; 140(1): 234-46. 